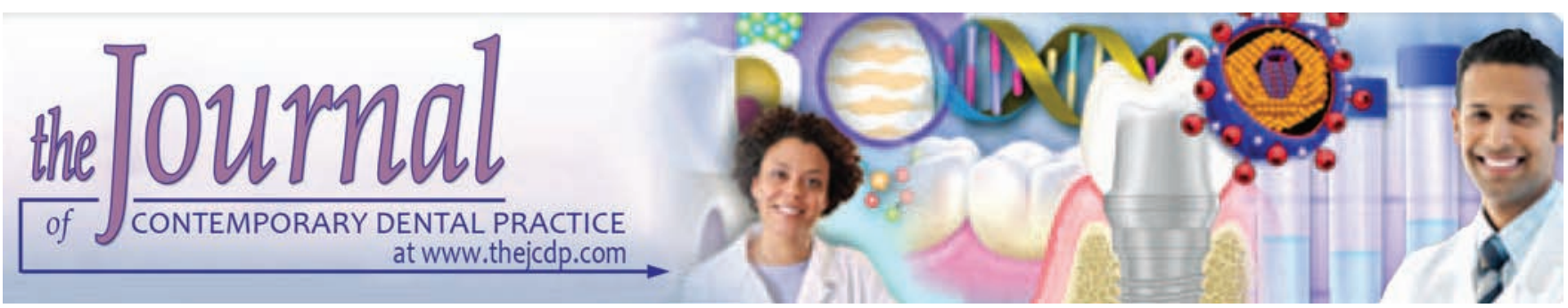

\title{
Nonsurgical Management of Adult Skeletal Class 3 with Deep Bite utilizing Mini-implants
}

\author{
${ }^{1}$ Ali G Alhalabi, ${ }^{2}$ Salah Mahaini, ${ }^{3}$ Ghalia Shebib, ${ }^{4}$ Khaldoun Darwich, ${ }^{5}$ Luai Mahaini
}

\begin{abstract}
Introduction: Malocclusions with anterior crossbite are a major esthetic and functional concern for patients. This case report presents a 27-year-old Syrian female who was diagnosed with a class 3 malocclusion, combined with anterior crossbite, deep bite, concave profile, and inadequate maxillary incisor exposure. There was a centric occlusion (CO)/centric relation (CR) discrepancy and the mandible could be manipulated to near edge-to-edge incisal relation.

Correction was done by class 3 intermaxillary elastics on upper and lower mini-implants for the first 6 months, followed by preadjusted edgewise appliance. The objective of implantsupported elastics was to adapt the patient for the CR condylar position without dental effect. Treatment was completed in 24 months with satisfactory dental and facial relationship.
\end{abstract}

Keywords: Centric relation, Deep bite, Mini-implants, Nonsurgical treatment, Skeletal class 3.

How to cite this article: Alhalabi AG, Mahaini S, Shebib G, Darwich K, Mahaini L. Nonsurgical Management of Adult Skeletal Class 3 with Deep Bite utilizing Mini-implants. J Contemp Dent Pract 2017;18(1):65-68.

\section{Source of support: Nil}

Conflict of interest: None

\footnotetext{
1,5 Department of Orthodontics, Damascus University, Damascus Syrian Arab Republic

${ }^{2}$ Department of Oral and Maxillofacial Surgery, LudwigMaximilians-Universität, Bavaria, Germany

${ }^{3}$ Department of Prosthodontics, Ernst-Moritz-Arndt-Universität Greifswald, Braunschweig, Germany

${ }^{4}$ Department of Oral and Maxillofacial Surgery, Damascus University, Damascus, Syrian Arab Republic

Corresponding Author: Ali G Alhalabi, Department of Orthodontics, Damascus University, Damascus, Syrian Arab Republic, Phone: +00963967803138, e-mail: alihalabi32t@ yahoo.com
}

\section{INTRODUCTION}

Skeletal class 3 malocclusions are very challenging to treat as the factors contributing to it are complex. ${ }^{1}$ They present with a combination of various skeletal types. Orthognathic surgery is the ideal treatment option for an adult with skeletal class 3 malocclusion. ${ }^{2}$ Patients with no remaining growth left and are unwilling for surgery can be camouflaged ${ }^{3}$ by orthodontic treatment with fixed appliances along with or without extractions and tooth movement relative to their supporting basal bone to compensate moderate degree of severity.

When a nonsurgical treatment is chosen, it is important to diagnose the cause of the skeletal problem in all planes of space and assess the severity of the case. ${ }^{4}$ A stable outcome requires careful consideration of the patient's biologic limitation to prevent adverse consequences, such as traumatic incisor occlusion, incisor mobility, and gingival recession. ${ }^{5}$

\section{CASE REPORT}

A female patient 27 years old was admitted to the Oral and Maxillofacial Surgery Hospital in Damascus University and referred to the Orthodontic Department. The chief complaint was poor dental esthetics and function due to the anterior crossbite.

Her facial photographs showed a concave profile (Fig. 1) and a class 3 appearance. The pretreatment intraoral photographs showed class 3 molar and canine relationships, $3.5 \mathrm{~mm}$ anterior crossbite, and $4 \mathrm{~mm}$ of deep bite (Figs 2A to D). The panoramic radiograph (Figs 3A and $B$ ) showed that all teeth were present except for the 3rd molars and missing lower 2nd premolar replaced with fixed bridges bilaterally, an impacted upper canine with retained deciduous canine on the right side.

Cephalometric analysis revealed a class 3 skeletal pattern. The ANB (A point, nasion, B point) angle of -4 and 


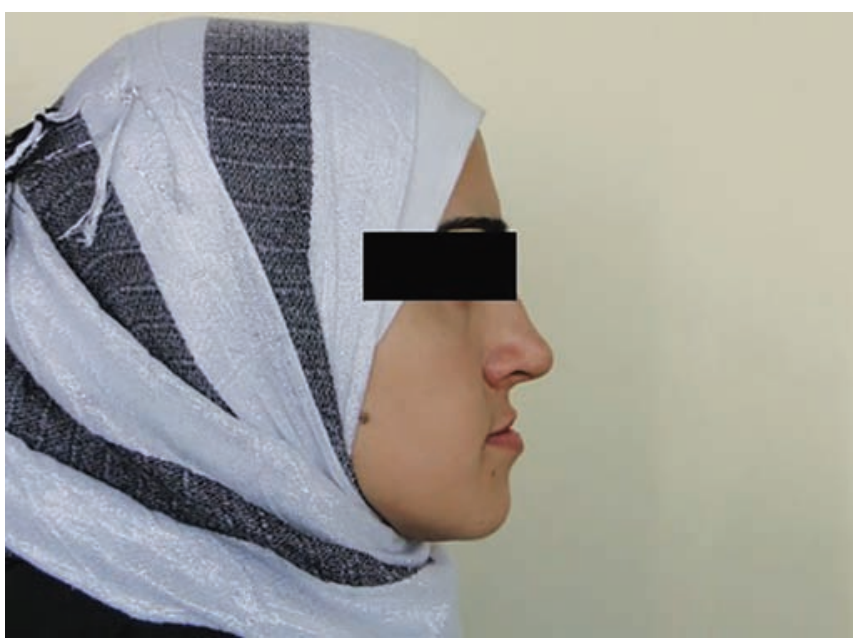

Fig. 1: Photographs showing a concave profile

the SNA angle of 77 indicated a retrognathic maxilla at low mandibular plane angle, and the incisor mandibular plane angle of 86 confirmed linguoversion of the lower anterior teeth.

Functional examination revealed a centric relation (CR)/ centric occlusion (CO) discrepancy of $4 \mathrm{~mm}$, but the patient could not achieve an edge-to-edge incisal relation. With manual manipulation, the mandible could be guided to a near edge-to-edge relation. No signs or symptoms due to joint dysfunction were present.

Based on these findings, this patient's malocclusion can be said to be due primarily to a skeletal discrepancy between the maxilla and the mandible, which resulted in dental tipping and extrusion on the anterior areas and adaptive mandibular position.

\section{Treatment Objectives}

- Restore mandibular position in CR

- Exposure and orthodontic traction of upper right canine

- Achieve ideal overbite and overjet relationship with stable occlusion without interferences in CR

- Improve smile and facial esthetics.

\section{Treatment Progress}

The treatment plan was explained to the patient and began once she gave consent. Mini-implants (1.3 mm diameter, 6 mm length; Absoanchor; Dentos Inc., Daegu, Korea) were inserted between the mandibular lateral incisor and canine teeth on both sides. Other bilateral mini-implants (1.6 mm diameter, $10 \mathrm{~mm}$ length; Absoanchor; Dentos
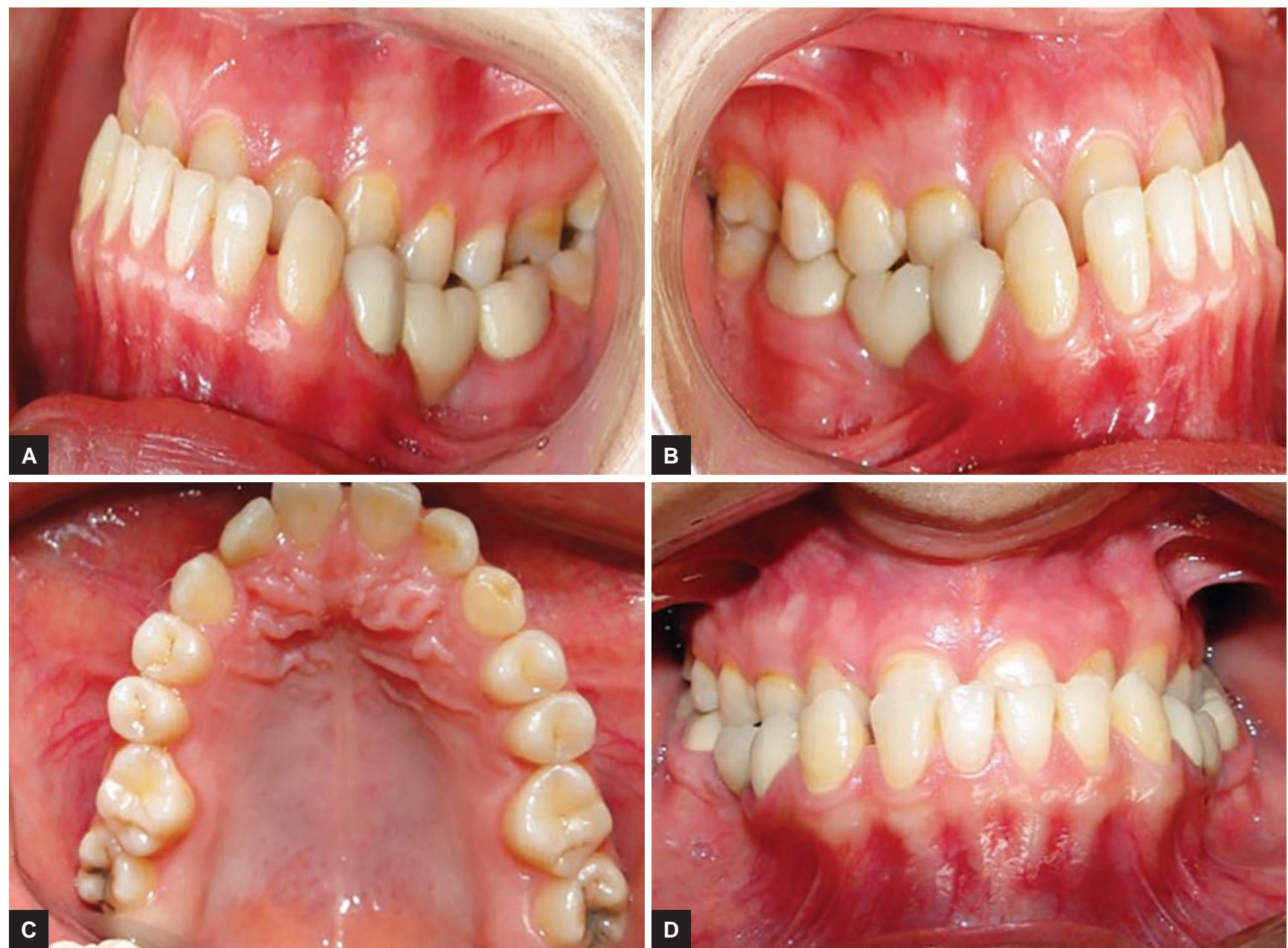

Figs $2 A$ to $D$ : The pretreatment intraoral photographs 

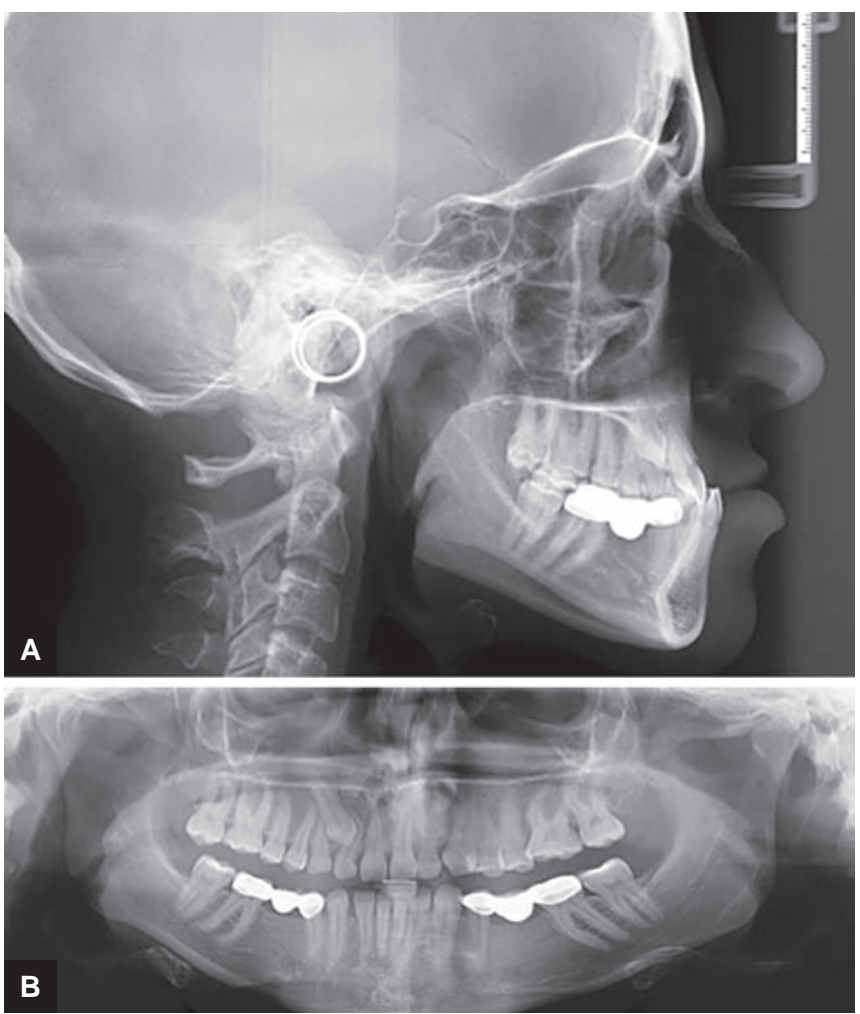

Figs 3A and B: Pretreatment radiograph
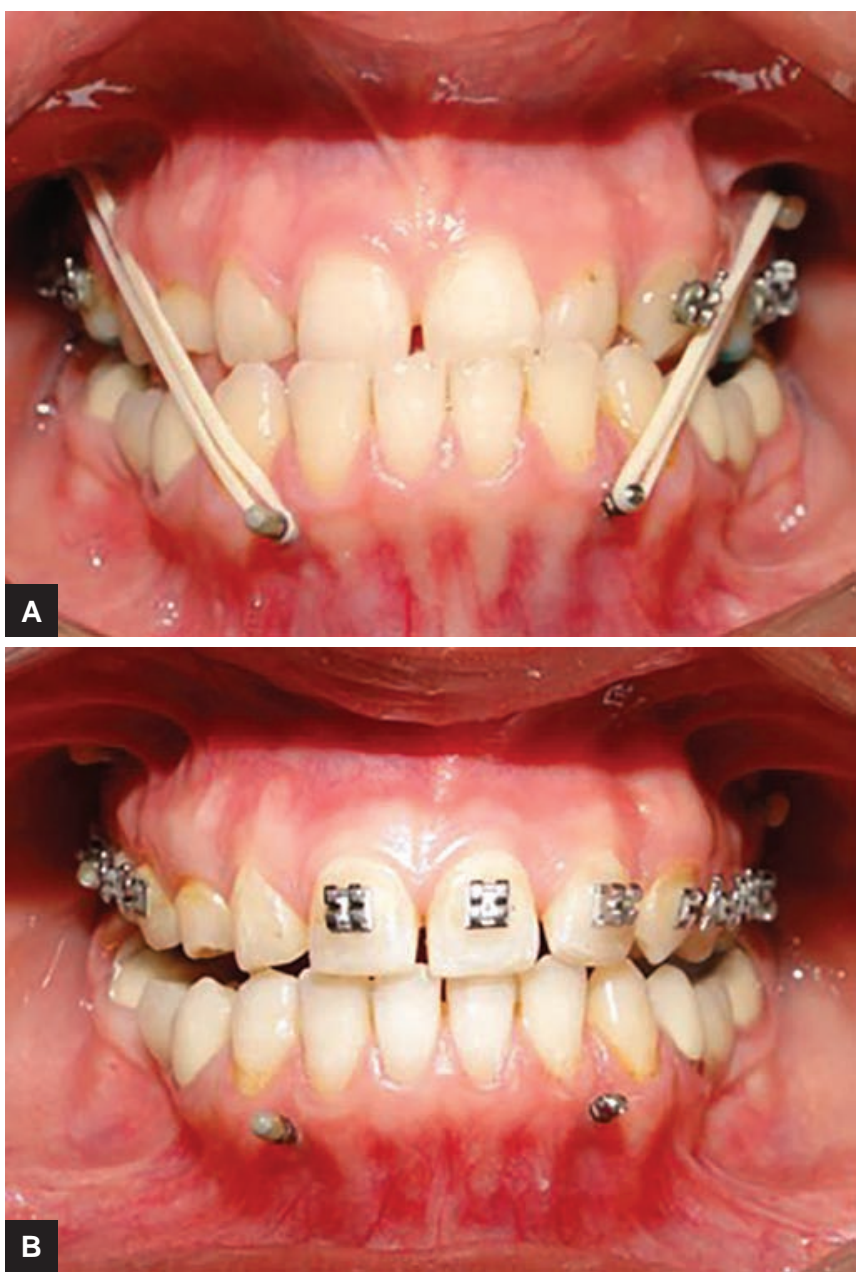

Figs 4A and B: Class 3 elastics applied on both sides
Inc., Daegu, Korea) were installed between the maxillary second premolar and molar teeth under the mucogingival line. Class 3 elastics were applied on both sides, (Figs 4A and B), gradually increasing the force to $200 \mathrm{gm}$ on both sides. A posterior bite rise was used to disengage the bite. The patient continued to use intermaxillary elastics for 6 months. During this time, the upper right canine was exposed surgically with open window technique and was monitored for spontaneous eruption.

After a stable mandibular position (Figs 5A to C) was maintained, an upper preadjusted edgewise appliance was bonded with transpalatal arch. A protraction utility arch was used to advance and torque the upper centrals and laterals. After achieving the desirable overjet and overbite, attachments for elastics were bonded on the fixed lower bridges and the bite rise was trimmed
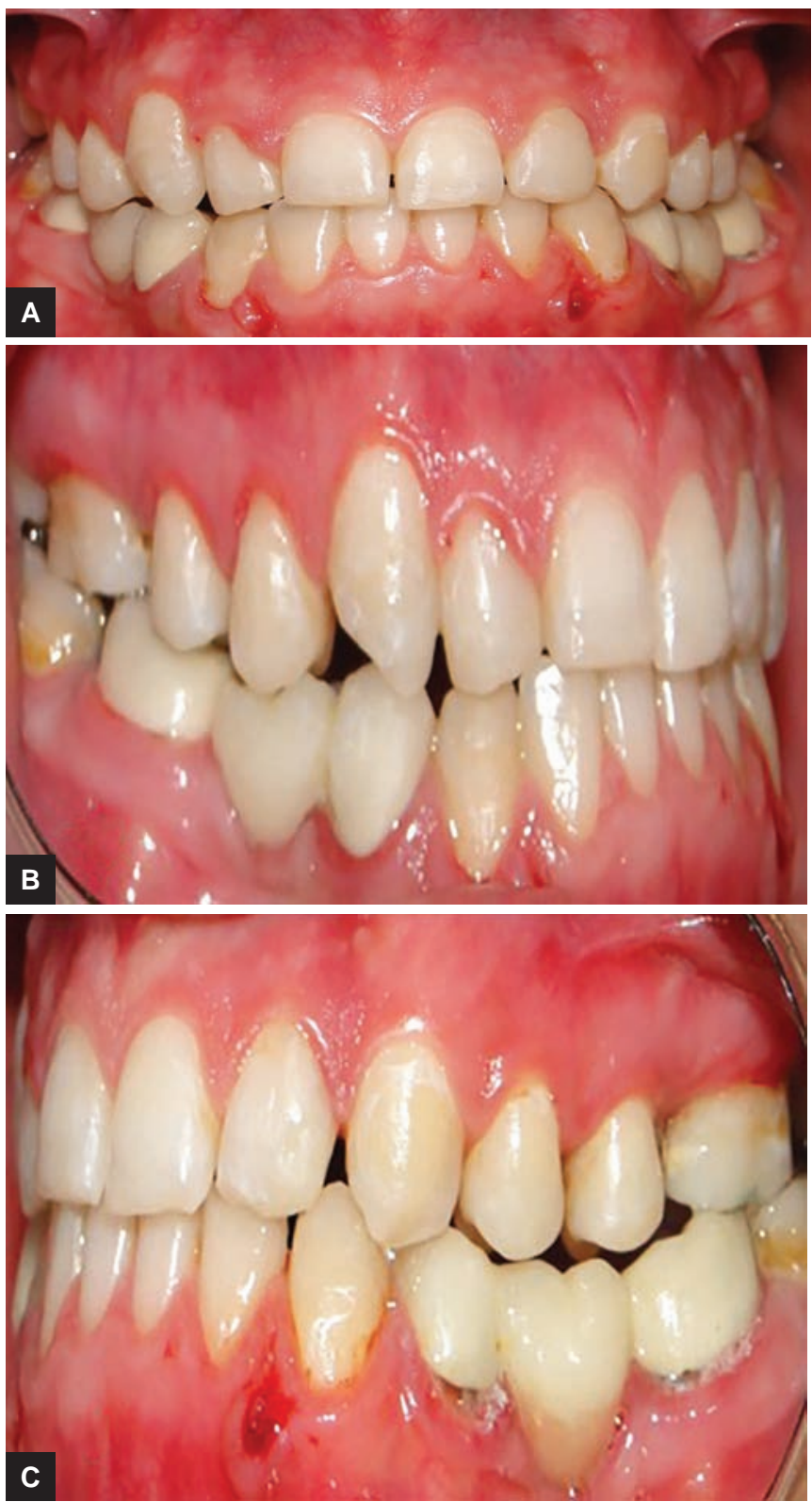

Figs 5A to C: Preadjusted edgewise appliance bonded with transpalatal arch 

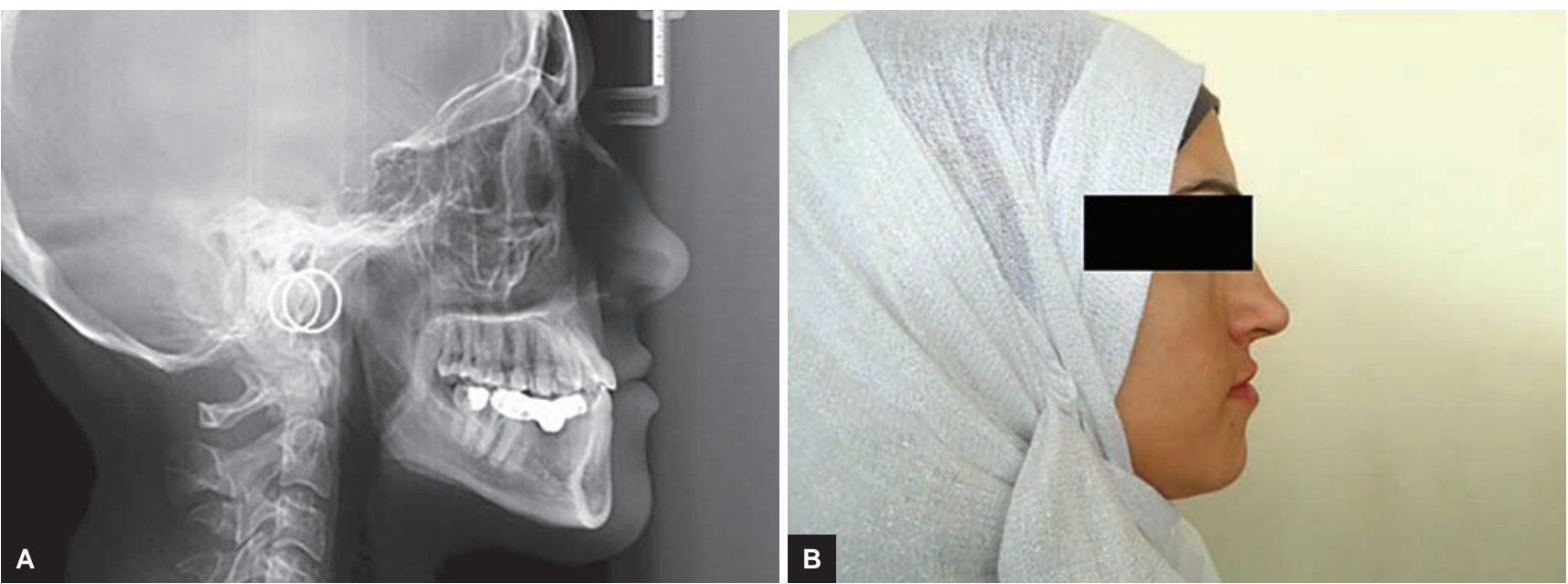

Figs 6A and B: Post treatment radiograph - upper dentition mesialized

Table 1: Cephalometric analysis

\begin{tabular}{llll}
\hline & Normal & $\begin{array}{l}\text { Before } \\
\text { treatment }\end{array}$ & $\begin{array}{l}\text { After } \\
\text { treatment }\end{array}$ \\
\hline SNA & $81 \pm 3$ & 77 & 80 \\
SNB & $79 \pm 3$ & 81 & 81 \\
ANB & $2 \pm 2$ & -4 & -1 \\
S N Pog & $79 \pm 3$ & 81 & 80 \\
N-S: SPP & $9 \pm 2$ & 9.5 & 10 \\
N-S: Go.Me & $34 \pm 4$ & 30.5 & 31 \\
N S Gn (Y-axis) & $68 \pm 3$ & 67 & 67 \\
B angle & $26 \pm 4$ & 24 & 24 \\
\hline
\end{tabular}

sequentially to allow extrusion for the upper posterior segment. The right upper canine was tracted and brought into alignment and finally the whole upper dentition was mesialized (Figs 6A and B).

\section{DISCUSSION}

Although the patient's mandible could be manipulated backward to near an edge-to-edge position, her occlusion was still diagnosed as a dental class 3 on both sides (Table 1). In addition, there was a low mandibular plane angle and class 3 compensation.

Mandibular manipulation is important for anterior crossbite patients to determine if there is a functional shift, and whether the malocclusion can be treated with conservative orthodontics, as opposed to extractions and/ or orthognathic surgery. Furthermore, the differences in the facial profile, when the mandible is positioned in $\mathrm{CO}$ and $\mathrm{CR}$, is helpful for understanding the probable outcome of treatment.

\section{CONCLUSION}

A dramatic dental and facial and esthetic improvement and occlusal function was achieved with completion of treatment. The patient was very happy with the results.

The increased treatment time and cost may call to question the use of such surgical intervention compared with other nonsurgical methods if done prior to the completion of growth.

\section{REFERENCES}

1. Tucker MR. Orthognathic surgery versus orthodontic camouflage in the treatment of mandibular deficiency. J Oral Maxillofac Surg 1995 May;53(5):572-578.

2. Proffit WR, Bailey LJ, Phillips C, Turvey TA. Long-term stability of surgical open-bite correction by Le Fort I osteotomy. Angle Orthod 2000 Apr;70(2):112-117.

3. Proffit WR, Fields HW, Sarver DM. Contemporary orthodontics. 4th ed. St Louis: Mosby; 2007. p. 6-14, 300-309.

4. Arnett GW, Bergman RT. Facial keys to orthodontic diagnosis and treatment planning - part II. Am J Orthod Dentofacial Orthop 1993 May;103(5):395-411.

5. Bishara SE. Facial and dental changes in adolescents and their clinical implications. Angle Orthod 2000 Dec;70(6):471-483. 